CLINICAL STUDY

\title{
Is there a further acceleration in the age at onset of menarche? A cross-sectional study in 1840 school children focusing on age and bodyweight at the onset of menarche
}

\author{
A M Bau ${ }^{1}$, A Ernert ${ }^{2}$, L Schenk ${ }^{3}$, S Wiegand ${ }^{1}$, P Martus $^{2}$, A Grüters $^{1}$ and H Krude ${ }^{1}$ \\ ${ }^{1}$ Institute for Experimental Pediatric Endocrinology, ${ }^{2}$ Institute for Biostatistics and Clinical Epidemiology and ${ }^{3}$ Institute for Medicine Sociology, Charité \\ University Medicine Berlin, Augustenburgerplatz 1, 13353 Berlin, Germany
}

(Correspondence should be addressed to A M Bau; Email: anne-madeleine.bau@charite.de)

\begin{abstract}
Objective: More than 30 years ago Frisch and Revelle proposed a body weight threshold for the onset of menarche. Based on this hypothesis, a further acceleration of age at menarche can be expected in times of childhood obesity.

Design: A cross-sectional study of 1840 healthy school girls (Berlin school children's cohort, BSCOC) within the age groups 10-15 years was conducted in 2006-2007.

Methods: Median age of menarche was calculated by Kaplan-Meier survival analysis. Bi- and multivariate analyses were performed to analyze the associations between menarche age and weight status. A locally weighted regression was used to analyze the relationship respectively between height, weight, and body mass index (BMI)-SDS and age stratified by menarche status.

Results: Nine hundred and thirty six (50.9\%) girls had already experienced menarche at a median age of 12.8 years. Two hundred and thirty six of these girls reached their menarche recently. Obese/overweight girls reached menarche significantly earlier (12.5 years), than normal weight (12.9 years), and underweight girls (13.7 years). The mean total body weight was similar in all girls at menarche irrespective of age (mean $51.1 \mathrm{~kg}$, S.D. 8.1) and height. BMI-SDS remained the only significant factor for onset of menarche within a multiple regression model for early menarche (OR 2.1, 95\% confidence interval 1.3-3.3, $P=0.002$ ).

Conclusions: Age at onset of menarche did not accelerate even in a childhood population with more than $10 \%$ obesity prevalence. Nevertheless, a negative correlation of BMI-SDS with age at onset of menarche exists.
\end{abstract}

European Journal of Endocrinology 160 107-113

\section{Introduction}

A secular trend in the onset of menarche has been described over the last 150 years (1). For example, in Germany the median age at menarche has decreased from 15.5 in 1869 to 12.5 in 1978 years (2). However, in recent years the onset of menarche has not decreased further and ranges between 12.5 and 13.0 years in most other European countries and the USA (3-11). The acceleration of menarche within the same populations over time argues for environmental factors as the main contribution to the timing of the onset of puberty. An improvement of nutritional supply during the time period of the secular trend is assumed as the most important trigger for the accelerated pubertal onset $(12,13)$. However, the molecular basis for this striking acceleration of human reproductive development is so far unknown.

In 1971 Frisch and Revelle (14) presented one of the first concepts linking nutrition and puberty when they postulated, based on longitudinal anthropometric data from 181 girls collected between 1929 and 1950 that a critical weight threshold seems to exist at which menarche starts. They proposed this "critical body weight hypothesis' based on the finding that the mean body weight of all girls in their cohorts, who experienced menarche was $47.8 \mathrm{~kg}$, irrespective of age and height. This hypothesis argues that the reproductive phase of female development is triggered at a fixed level of body weight. A close interplay of nutrition and timing of puberty seems to be meaningful in terms of biological efficiency of reproduction since the outcome of pregnancy and childbirth will be secured by an adequate level of stored calories as fat tissue. The ontology of body weight change during childhood also argues for such a close link of deposition of fat stores and the initiation of menarche. During the last years, it was observed that the ratio of the amount of body weight relative to height, calculated as the body mass index (BMI), rises constantly during the prepubertal years of 
childhood. This increase in the amount of body fat stores, especially during the female prepubertal time period, might be an important signaling of the preparedness for reproduction to the central hypothalamic neurons that induce puberty.

The existence of such a critical body weight set point as the key trigger for pubertal onset could explain, at least in part, the secular trend of menarche during the last 150 years. Such a critical body weight hypothesis would predict that in populations with increasing prevalence of childhood obesity, the secular trend of menarche will further significantly accelerate. Indeed, during the last 10 years, the prevalence of obesity has continued to increase tremendously in the USA as well as in Europe (15-18). The most recent surveys revealed that more than $18 \%$ of children in an age range of pubertal onset are overweight. In addition, several large surveys in the USA (NHANES, PROS, and Bogalusa Heart Study) have shown that on average girls who reached menarche have a higher BMI than girls before menarche. However, so far discussion of the further acceleration of age of menarche in cohorts of girls with high prevalence of obesity has been controversial $(9,19-23)$. Because in many studies, menarche is determined by a single time point observational assessment, for example, asking girls whether they had already had their first menstruation at the time of the survey or not. In such a study population, a 13 years old girl might have reached menarche more than 2 years before, and since then her weight and height could have changed significantly. This methodological problem presented in the available studies suggests that the data are not conclusively informative in terms of the actual body weight at the time of menarche and it cannot be dismissed that an increase of the weight might occur as a consequence of menarche rather than as a permissive factor for menarche.

To avoid these methodological and conceptual concerns and to investigate the actual relevance of a weight threshold for menarche as postulated more than 30 years ago, we performed a cross-sectional study in Berlin in 2006 and 2007 enrolling 1840 healthy girls of an age of 10-15 years of whom 236 had reached menarche within the proceeding 6 months.

\section{Methods}

A cross-sectional study Berlin school children's cohort (BSCOC) was conducted during September 2006 and March 2007 in Berlin schools. A sample size of 2400 girls was intended. This sample size was based upon the following assumptions: a) relevant effect, standardized difference (mean divided by s.D.) $=0.25, b$ ) the number of primary tests $=3, \mathrm{c}$ ) the level of significance for each test $0.05 / 3=0.017$, two-sided, d) Power $=0.8$, e) unequal group sizes, ratio $=0.176, \mathrm{f}$ ) assumed dropout rate $5 \%$. Girls were recruited by teachers at schools from 11 out of the 12 districts of Berlin; the survey group was randomly selected from both primary and secondary schools. In 68 schools, out of the 160 approached, $1840(40.8 \%)$ girls within the age range 10-15 could be enrolled. Information about nutrition, sports, and leisure habits; the frequency of sporting activities, the quality of life, ethnic, and migration background as well as mother's language were collected based on standardized questionnaire covering 80 items. A two-page questionnaire about their migration, ethnic, and social background was filled in by $91.3 \%$ of the girls' parents $(n=1683)$. All parents signed a letter of consent that their child participates in the study. The study was approved by the local ethical committee.

One single study nurse measured weight, height, waist, and hip measurements. Weight was measured without shoes and in underwear, with a calibrated portable electronic digital scale weighing machine (SECA model 862, Germany) with a precision of $0.01 \mathrm{~kg}$. Height was measured using a portable statometer (SECA 214) to the nearest $0.1 \mathrm{~cm}$. BMI, BMI percentiles and BMI-SDS were calculated according to Kromeyer-Hauschild et al. and Cole $(24,25)$. Girls were categorized as 'underweight' when BMI was under the 10th percentile, as 'normal weight' when BMI was between 10th and 90th percentile and as 'overweight and obese' when BMI was above 90th and 97 th percentile respectively.

The same study nurse interviewed all girls to determine as accurately as possible the date of their first menstrual bleeding. Most girls were able to remember undoubtedly the month and the year of their menarche. For those girls that could not remember an estimate was made and the date narrowed (26). The girls were than categorized according their menarche status as 'not yet started', 'occurred within 6 months' and 'occurred more than 6 months ago'. For a further differentiation in a multiple logistic regression of early and late menarche, we grouped 'early' menarche 12 years and younger $(\leq 144$ months, $n=35)$ and 'late' menarche 12.1 years and older ( $>144$ months, $n=201$ ) according to age limits as defined by the German health survey (27). Additional information concerning earlier signs of pubertal onset like growth acceleration and onset of breast development (thelarche) were not included due to methodological and ethical problems of palpation of the breast in our investigation setting.

Migration background was defined, as suggested by Schenk et al. (28). If no information from the parents was available but girls were born in Germany and have German nationality, the language spoken at home was chosen to categorize the migration background.

Social status score was calculated by the educational background of parents and their professional life as developed by Bettge et al. (29).

All data analyses were performed by using SPSS release 14.0. Mean with 95\% confidence interval 
(CI 95\%) and median age at menarche was calculated by Kaplan-Meier survival analysis. Associations between menarche age and weight status were analyzed by Kruskal-Wallis and test of linearity using Jonckheere-Terpstra test (30). A stepwise multiple logistic regression was used to calculate adjusted odds ratios for social status, (lower, middle, and higher), migration background, (no migrant, one or two-sided migration background), and BMI-SDS in order to evaluate the influence of these variables on precocity. The level of significance was 0.05 (two-sided) for all statistical tests. A locally weighted regression (LOESS, $(31,32)$ ) was used to analyze the relationship respectively between height, weight, and age (in months) stratified by menarche status. The predicted values of the locally weighted regression are presented graphically and for the relationship of BMI-SDS and age at menarche the mean values were analyzed with a linear regression.

\section{Results}

Of the 1840 girls enrolled in the study, 936 (50.9\%) had already experienced menarche. Mean and median age of menarche was 12.8 years (154 months; 95\% CI: 153$155)$ as calculated by Kaplan-Meier analysis (Fig. 1). Menarche had occurred within the last 6 months in 236 of these girls. To evaluate the influence of body weight on the onset of menarche we stratified the subgroup of 236 girls with recent onset into underweight, normal weight, and obese-overweight according to BMI percentiles (25). Based on these definitions $4.2 \%$ were underweight (BMI $<10$ th percentile), $84.7 \%$ were normal weight (BMI 10th-90th percentile) and $11.1 \%$ were obese-overweight $(\mathrm{BMI}>90$ th percentile). Overweight and obese girls reached menarche

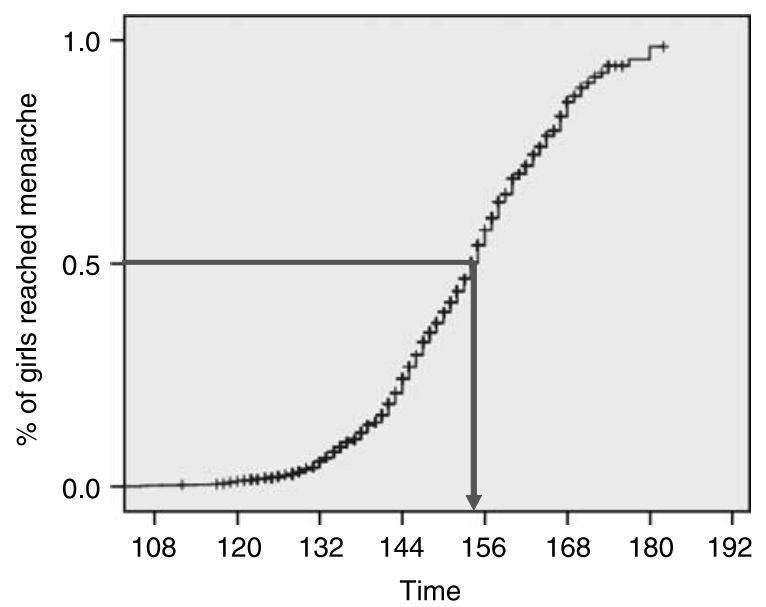

(Age at onset of menarche in months)

Figure 1 Mean and median age of menarche in months of the present study population (median age 12.8 years, 154 months (Cl 153-155)). significantly earlier (mean age at menarche 12.5 years, 150.5 months) than normal weight (mean age at menarche 13 years, 155.5 months) and underweight girls (mean age at menarche 13.7 years, 164.5 months; Fig. 2; Table $1, P<0.001)$. There was no significant association of onset of menarche and social background or migration status (Table $1, P>0.05$ ).

Accordingly in the multivariate analysis only BMISDS was significantly associated with precocity. Higher BMI-SDS were twice as likely the factor of early onset of menarche (OR 2.1 95\%, CI 1.3-3.3, $P=0.002$ ).

For a direct comparison of the data of Frisch et al. published in 1971 (14), obtained between 1929 and 1950, we analyzed the height and weight in the subsample of 236 girls who reached menarche within the last 6 months (Table 2). Irrespective to age and height, mean and median weight of girls who reached menarche recently did not depend on age and body height in this subgroup. In the Frisch cohort, menarche occurred at a weight of $47.8 \mathrm{~kg}$, while in this study girls close to menarche had a mean weight of $51.1 \mathrm{~kg}$. In both studies, the girls with menarche at an earlier age were smaller while the girls, who are older at menarche, were taller. We further analyzed the finding of similar body weight irrespective of age and height in the 236 girls by a locally weighted regression of height-, weight-, and age-adjusted BMI (BMI-SDS) of all girls included in our study in relation to age stratified by 'menarche status' (Fig. 3a-c).

In girls who reached menarche within the last 6 months $(n=236$, weight $51.1 \pm 8.1 \mathrm{~kg})$ as well as in girls who had experienced menarche longer than 6 months ago $(n=700$, weight $55.4 \pm 9.6 \mathrm{~kg})$, weight did not depend on the age of the subjects (Table 2, Fig. 3a). In contrast to weight, the height at onset of menarche in the 236 girls who reached menarche within the last

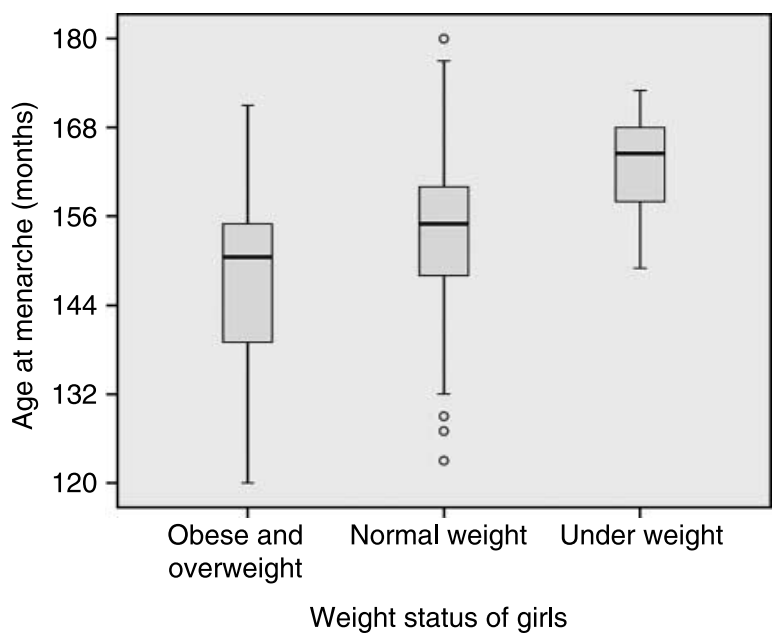

Figure 2 Box plots (quartiles) of age at menarche by weight status of girls (reference by Kromeyer-Hauschild et al. (2001), $n=236$; Kruskall-Wallis test, $P<0.001$ ). 
Table 1 Quartiles of menarche age (months) regarding weight status, social status, and migration background.

\begin{tabular}{|c|c|c|c|}
\hline & \multicolumn{2}{|c|}{ Menarche age (months) } & \multirow[b]{2}{*}{$P$ values } \\
\hline & $n$ & $\begin{array}{c}\text { Median } \\
\text { (25 and } 75 \text { quartiles) }\end{array}$ & \\
\hline Weight status & & & $<0.001$ \\
\hline Obese/overweight & 26 & $150.5(138.8 ; 155.0)$ & \\
\hline Normal weight & 200 & $155.0(148.0 ; 160.0)$ & \\
\hline Underweight & 10 & $164.5(157.5 ; 168.3)$ & \\
\hline Social status & & & 0.29 \\
\hline Lower & 42 & 154.5 (152.0; 159.3) & \\
\hline Middle & 79 & $154.0(147.0 ; 159.0)$ & \\
\hline Higher & 83 & $155.0(147.0 ; 162.0)$ & \\
\hline Migration background & & & 0.53 \\
\hline None & 141 & $155.0(148.0,160.0)$ & \\
\hline One-sided & 18 & $152.0(148.5 ; 161.5)$ & \\
\hline Two-sided & 57 & $152.0(147.0 ; 159.5)$ & \\
\hline
\end{tabular}

$P$ values by Jonckheere-Terpstra test.

6 months correlated well with age (Fig. 3b). Mean height $(161.6 \pm 6.3 \mathrm{~cm})$ of the girls, who had menstrual bleedings for longer than 6 months was not dependent on age, while the girls who had not reached menarche yet have a height that correlated with age. These analyses confirm and support the data presented in Table 2, that girls who not yet had reached menarche are still growing and increase their weight, while the girls, who had just experienced menarche showed an increasing body height but not an increasing body weight, and girls in whom menarche occurred a longer time ago weight and height had attained stable values. The finding of a similar weight with a significant lower height in the girls reaching menarche at an earlier age implicates higher BMI values in these girls. Accordingly we found higher BMI-SDS values with the age of menarche in girls with menarche at an earlier age (Fig. 3c). The BMI-SDS decreased 0.032 points per months (0.38 points per year) in the group with menarche during the last 6 months and 0.025 points per months $(0.30$ points per year) in the group with menarche longer than 6 months ago. The difference of 0.38 points versus 0.30 points per year was not significant $(P>0.2)$.

\section{Discussion}

We performed a recent survey from 2006 to 2007 to reinvestigate the Frisch hypothesis of a weight threshold for menarche in times of increasing prevalence of childhood obesity (14). Based on our actual data from 1840 girls in Berlin we found a mean age of menarche of 12.8 years ( 154 months). Therefore, a further secular trend of the mean age of menarche seems indeed not to occur because the median age of menarche was similar to 20 years ago when Kahl et al. conducted a crosssectional study in the same geographical area revealing a mean age of menarche of 12.8 years (33). Actual data from another German cross-sectional study conducted in 2003-2006 found consistently the same mean age at menarche of 12.8 years (CI 95\%, 12.8-12.9 years) as in our study $(27,34)$.

We compared the age of menarche in the underweight $(4.2 \%)$, normal weight $(84.7 \%)$, and obeseoverweight $(11.1 \%)$ subgroups, which revealed a significant difference of earlier onset of menarche in the obese-overweight group compared with the normal weight group (5 months) and a further difference compared with the underweight group (10 months). The difference of on average 5 months in the $11.1 \%$ of obese and overweight girls however, is too small to influence the overall mean age of menarche of the, whole cohort. However, this significant difference would predict that a further increase in the prevalence of

Table 2 Height $(\mathrm{cm})$ and weight $(\mathrm{kg})$ at onset of menarche per accomplished age group 1929-1950 (in the USA by Frisch et al. (1971)) and 2006-2007 (in the Germany, Berlin school children's cohort).

\begin{tabular}{|c|c|c|c|c|c|}
\hline \multirow[b]{2}{*}{ Age } & \multicolumn{2}{|c|}{ USA 1929-1950 } & \multicolumn{3}{|c|}{ Berlin 2006-2007 } \\
\hline & $N$ & Mean \pm S.D. & $N$ & Mean \pm s.D. & $\begin{array}{c}\text { Median } \\
\text { (25 and } 75 \text { quartile) }\end{array}$ \\
\hline \multicolumn{6}{|l|}{$<12$} \\
\hline $\begin{array}{l}\text { Height } \\
\text { Weight }\end{array}$ & 35 & $\begin{array}{r}156.4 \pm 5.7 \\
47.9 \pm 6.5\end{array}$ & 22 & $\begin{array}{c}153.4 \pm 6.9 \\
50.3 \pm 10.2\end{array}$ & $\begin{array}{l}152.0(149 ; 157.9) \\
50.8(42.9 ; 56.1)\end{array}$ \\
\hline \multicolumn{6}{|r|}{ 年, } \\
\hline $\begin{array}{l}\text { Height } \\
\text { Weight }\end{array}$ & 60 & $\begin{array}{r}158.0 \pm 5.6 \\
48.7 \pm 7.4\end{array}$ & 70 & $\begin{array}{r}158.9 \pm 5.8 \\
50.2 \pm 7.4\end{array}$ & $\begin{array}{l}159.8(155.4 ; 162.8) \\
48.9(45.6 ; 54.7)\end{array}$ \\
\hline \multicolumn{6}{|l|}{13} \\
\hline Height & 54 & $159.1 \pm 7.4$ & 106 & $161.7 \pm 6.0$ & $161.6(157.5 ; 165.6)$ \\
\hline Weight & & $47.2 \pm 6.8$ & & $51.8 \pm 8.5$ & $50.7(46.0 ; 55.0)$ \\
\hline \multicolumn{6}{|l|}{$\geq 14$} \\
\hline Height & 32 & $160.9 \pm 7.9$ & 38 & $162.8 \pm 5.7$ & $162.4(158.4 ; 166.5)$ \\
\hline Weight & & $47.2 \pm 6.8$ & & $51.0 \pm 6.7$ & $49.9(46.0 ; 55.0)$ \\
\hline \multicolumn{6}{|l|}{ Total } \\
\hline Height & 181 & $158.5 \pm 6.8$ & 236 & $160.3 \pm 6.5$ & $160.7(156.4 ; 164.0)$ \\
\hline Weight & & $47.8 \pm 6.9$ & & $51.1 \pm 8.1$ & $49.9(45.9 ; 54.9)$ \\
\hline
\end{tabular}



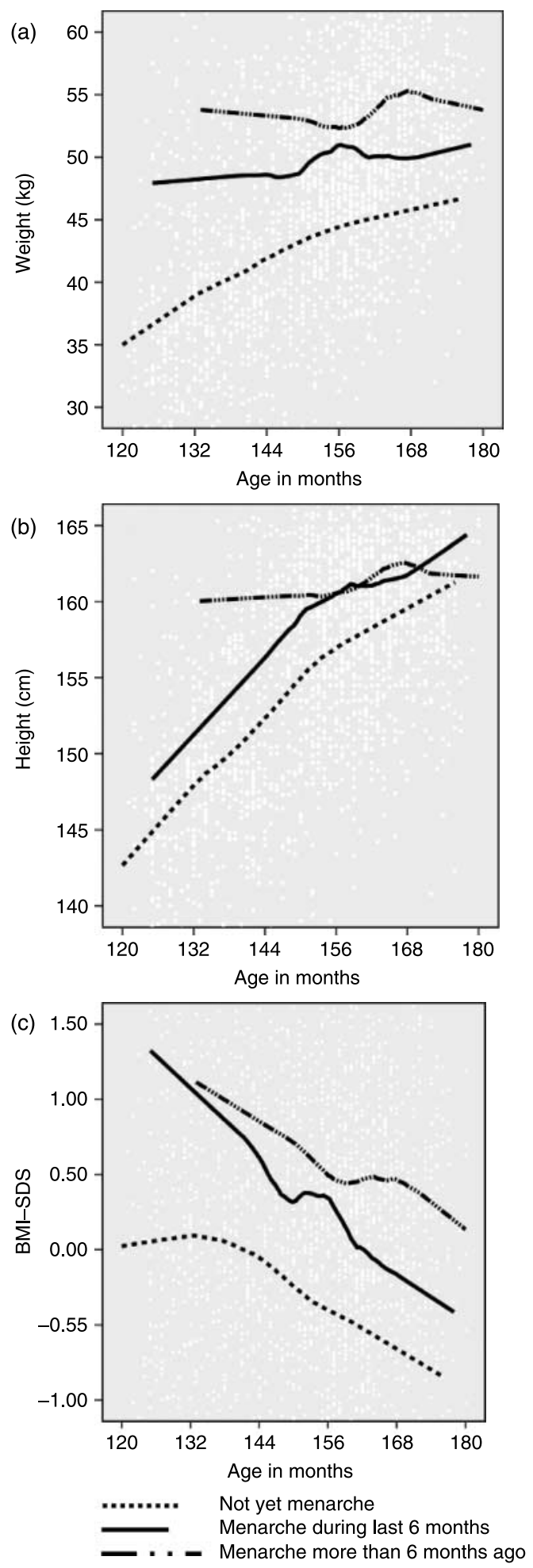

Figure 3 (a) Locally weighted regression for weight at menarche status and age in months. (b) Locally weighted regression for height at menarche status and age in months. (c) Locally weighted regression for BMI-SDS at menarche status and age in months. (Menarche status means not yet menarche (the lower broken line) $n=903$, menarche during last 6 months (continuous line) $n=236$, menarche more than 6 months ago (the upper interrupted line) $n=700$ ). childhood obesity beyond the actual level of $11.1 \%$ would potentially further accelerate the age of the onset of menarche. Even in a worst scenario of an extremely high childhood obesity prevalence of $100 \%$, the expected secular trend would not exceed the 5 months difference as we found in the obese-overweight subcohort of our study population. Together, these data imply that a measurable effect of obesity prevalence on the age of onset of menarche exists, but that the amount of further acceleration that might be caused by childhood obesity will be less than the acceleration that was observed during the last 150 years, which exceeded in some populations 5 years.

Moreover, our data suggest that the main factor for the secular trend of menarche during the last century was most likely not the change in nutritional status. We observed in our underweight sub-cohort a delay of menarche of only 10 months compared with the actual 'normal weight' group. The weight of the contemporary underweight girls is similar or even lower than the weight which was measured in the female populations a century ago when menarche occurred at an age of 1517 years (35). Based on these data we assume that the maximum effect of a change from the historic undernutrition to actual 'normal' nutrition states had not exceeded $\sim 1$ year of acceleration. Therefore, although it is attractive to explain the secular trend of menarche by an enhanced nutritional supply that was gained during the last century, most likely factors other than nutrition were more causative in advancing the onset of menarche for more than 3 years.

To reexamine the 'critical body weight hypothesis' of Frisch and Revelle presented in 1971 (14) we compared the mean and median weight and height of our actual Berlin study population with the same age groups, height, and weight data collected more than 50 years ago.

The girls from the actual Berlin cohort are on average $1.8 \mathrm{~cm}$ taller, which is in accordance with the welldocumented height acceleration during the last 50 years $(5,36,37)$. The weight of the girls in all subgroups of the study was on average $3.3 \mathrm{~kg}$ higher than that of the girls from the Frisch cohort. This difference in mean weight after the 50 year time period can be explained by the additional body weight that is gained by the secular increase of height difference of $1.8 \mathrm{~cm}$ as calculated by Cole et al. (5) and therefore does not reflect the higher rate of obesity. Besides these secular trends in height and weight, we found of special interest, as did Frisch and Revelle (14) in 1929-1950, that the mean body weight was similar in all girls, who reached menarche recently, irrespective of their age. This reconfirmation of the key finding after 50 years, that on average all girls experience menarche at the same level of body weight, indeed implicates a body weight threshold for the initiation of menarche as suggested by the 'critical body weight hypothesis' in 1971. 
However, it has to be kept in mind that recent evidence does not support such an interpretation of these striking epidemiological findings. Up to now the only known signal that transmits the state of nutrition to the reproduction relevant hypothalamus neurons is the hormone leptin. Leptin is secreted from the fat tissue in direct proportion of the amount of total fat mass. Leptin binds to neurons that secrete GnRH and in the absence of leptin either by a genetic defect of the leptin gene or in states of severe underweight, GnRH deficiency results. Because leptin substitution can restore the normal secretion of GnRH in these pathological conditions $(38,39)$, a permissive role of leptin for the induction of puberty and the onset of menarche, which is characterized by a cyclic secretion of $\mathrm{GnRH}$, has been postulated. Therefore, if puberty is triggered by the nutritional state of an individual, the amount of fat tissue via leptin would be most likely the critical parameter. Total body weight does not represent accurately the body fat mass since the lean mass is related to the height of an individual, which is critically relevant in growing children. The BMI, which includes the ratio of weight to the square of height, represents a more accurate measurement that reflects at least in part body fat mass compared with the total body weight. If a threshold exists that reflects the nutrition state as a trigger for the onset of menarche than the BMI would be a more promising candidate parameter to be similar in girls at the onset of menarche compared with the body weight. When we calculated the age-adjusted BMI values (BMI-SDS) we found no 'BMI threshold' for menarche. By contrast, a linear negative correlation of BMI-SDS with the age of menarche was evident. These data clearly suggest that the BMI and respectively the body fat mass influence the onset of menarche but not in terms of a threshold. More likely the onset of menarche is modified by the BMI-SDS rather than initiated. Other endogenous or environmental factors, which need to be determined, seem to trigger the initiation of menarche irrespective of the fat mass. BMI, fat mass, and leptin most likely act as permissive factors for the initiation of puberty with menarche not being possible in a situation of severe underweight and only as a partial modifier of menarche in terms of a discrete acceleration of menarche in overweight and obese girls. Further longitudinal studies in actual obese childhood cohorts with inclusion of early signs of puberty like growth acceleration and onset of breast development would be warranted to depict the detailed causal relationship of overweight and the onset of puberty.

In conclusion, the observation of an equal body weight in girls at the onset of menarche irrespective of age and height, as described by Frisch and Revelle already in 1971 is puzzling regarding the current knowledge about the interplay of fat mass, leptin, and the GnRH neurons, which would suggest that BMI rather than total body weight is the relevant parameter to be more tightly correlated with the timing of menarche. The similar body weight in the girls at menarche therefore does not represent the 'real' biological signal as suggested by Frisch and Revelle but, due to lower height of these girls, rather reflects a higher fat mass and therefore a higher leptin level, which is the biological relevant signal.

\section{Declaration of interest}

There is no conflict of interest that could be perceived as prejudicing the impartiality of the research reported.

\section{Funding}

The study Berlin school children's cohort (BSCOC) was funded by the EU FP 6 Network of Excellence 'Environmental and endogenous factors influencing puberty onset. Programming effects of early nutrition on long-term health' 2005-2008 reference no. 513991 puberty onset - influence of environmental and endogenous regulators (PIONEER).

\section{Acknowledgements}

This survey was only possible due to the assistance and support of many people. The authors would like to express their highest gratitude to the participating schools, teachers, girls, and their parents and their kind cooperation. Our warmest thanks to Ingrid Rehwald who measured and interviewed all the girls patiently as well as the other members of the survey team. Special thanks go to all partners who were helpful in their critical discussions.

\section{References}

1 Parent AS, Teilmann G, Juul A, Skakkebaek NE, Toppari J \& Bourguignon JP. The timing of normal puberty and the age limits of sexual precocity: variations around the world, secular trends and changes after migration. Endocrine Reviews 200324 668-693.

2 Reißig M. Körperliche Entwicklung und Akzeleration Jugendlicher. Ergebnisse einer Längsschnittuntersuchung an Schülern vom 12.16. Lebensjahr, pp 86-88. Berlin: Verlag Volk und Gesundheit, 1985.

3 Ostersehlt D \& Danke-Hopfe H. Changes in the age at menarche in Germany: evidence for a continuing decline. American Journal of Human Biology 19913 647-654.

4 Danke-Hopfe H. Menarcheal age in Europe. Yearbook of Physical Anthropology 198629 81-112.

5 Cole TJ. Secular trends in growth. Proceedings of the Nutrition Society 200059 317-324.

6 Juul A, Teilmann G, Scheike T, Hertel NT, Holm K, Laursen EM, Main KM \& Skakkebaek NE. Pubertal development in Danish children: comparison of recent European and USA data. International Journal of Andrology 200629 247-255.

7 Herman-Giddens ME, Kaplowitz PD \& Wasserman R. Navigating the recent articles on girls' puberty in pediatrics: what do we know and where do we go from here? Pediatrics 2004113 911-917.

8 Herman-Giddens ME. The decline in the age of menarche in the United States: should we be concerned? Journal of Adolescent Health 200740 201-203.

9 Anderson SE, Dallal GE \& Must A. Relative weight and race influence average age at menarche: results from two nationally representative surveys of USA girls studied 25 years apart. Pediatrics $2003111844-850$.

10 Anderson SE \& Must A. Interpreting the continued decline in the average age at menarche: results from two nationally representative surveys of USA girls studied 10 years apart. Pediatrics 2005 $147753-760$ 
11 Freedman D, Khan L, Serdula M, Dietz W, Srinivasan S \& Berenson G. Relation of age of menarche to race, time period and anthropometric dimensions: the Bogalusa Heart Study. Pediatrics 20021104.

12 Thomas F, Renaud F, Benefice E, de Meeüs T \& Guegan JF. International variability of ages at menarche and menopause: patterns and main determinants. Human Biology 200173 271-290.

13 Gluckman PD \& Hanson MA. Changing times: the evolution of puberty. Molecular and Cellular Endocrinology 200625 254-255.

14 Frisch R \& Revelle R. Height and weight at menarche and hypothesis of menarche. Archives of Disease in Childhood $1971 \mathbf{4 6}$ 695-701.

15 Wang Y \& Lobstein T. Worldwide trends in childhood overweight and obesity. International Journal of Pediatric Obesity 20061 11-25.

16 CDC Homepage: http://www.cdc.gov/nccdphp/dnpa/obesity/January, 2008.

17 Kosti RI \& Panagiotakos DB. The epidemic of obesity in children and adolescents in the world. Central European Journal of Public Health 200614 151-159.

18 Kurth BM \& Schaffroth Rosario A. Die Verbreitung von Übergewicht und Adipositas bei Kindern und Jugendlichen in Deutschland. Ergebnisse des Kinder- und Jugendgesundheitssurvey. Bundesgesundheitsblatt, Gesundheitsforschung, Gesundheitsschutz $2007 \mathbf{5 0}$ 736-743.

19 Wattigney W, Srinivasan SR, Chen W, Greenlund KJ \& Berenson GS. Secular trend on earlier onset of menarche with increasing obesity in black and white girls: the Bogulusa Heart Study. Ethnicity and Disease 19999 181-189.

20 Adair L. Size at birth predicts age at menarche. Pediatrics 2001 107 e 59.

21 Kaplowitz PB, Slora EJ, Wassermann RC, Pedlow SE \& HermanGiddens ME. Earlier onset of puberty in girls: relation to increased body mass index and race. Pediatrics 2001108 347-353.

22 Wang YF. Is obesity associated with early sexual maturation? A comparison of the association in American boys versus girls Pediatrics $2002110903-910$.

23 Davision KK, Susman EJ \& Birch LL. Percent body fat at age 5 predicts earlier pubertal development among girls at age 9 . Pediatrics $2003111815-821$.

24 Cole TJ, Bellizzi MC, Felgal KM \& Dietz WH. Establishing a standard definition for child overweight and obesity worldwide: international survey. BMJ $2000 \mathbf{3 2 0} 1240$.

25 Kromeyer-Hauschild K \& Wabitsch M. Perzentile für den bodymass-index für das Kindes-und Jugendalter unter Heranziehung verschiedener deutscher Stichproben. Monatsschrift für Kinderheilkunde $2001149807-818$.

26 Koo MM \& Rohan TE. Accuracy of short-term recall of age at menarche. Annals of Human Biology 199724 61-64.

27 Kahl H, Schaffroth Rosario A \& Schlaud M. Sexuelle Reifung von Kindern und Jugendlichen in Deutschland. Ergebnisse des Kinderund Jugendgesundheitssurvey. Bundesgesundheitsblatt, Gesundheitsforschung, Gesundheitsschutz $2007 \mathbf{5 0} 677-685$.
28 Schenk L, Ellert U \& Neuhauser H. Kinder und Jugendliche mit Migrationshintergrund in Deutschland. Methodische Aspekte im Kinder- und Jugendgesundheitssurvey (KIGGS). Bundesgesundheitsblatt, Gesundheitsforschung, Gesundheitsschutz 200750 590-599.

29 Bettge S, Oberwöhrmann S, Delekat D, Häßler K, Hermann S \& Meinlschmidt G. Zur gesundheitlichen und sozialen Lage von Kindern in Berlin, Ergebnisse und Handlungsempfehlungen auf der Basis der Einschulungsuntersuchung 2004. Spezialbericht 2006-1. Senatverwaltung für Gesundheit, Soziales und Verbraucherschutz, pp 66-68, 2006.

30 Conover WJ. Practical Nonparametric Statistics. 3 New York, USA: John Wiley \& Sons, 1999.

31 Cleveland WS \& Devlin SJ. Locally weighted regression: an approach to regression analysis by local fitting. Journal of the American Statistical Association $1988 \mathbf{8 3} 596-610$.

32 Cleveland WS, Grosse E \& Shyu WM. Local regression models. In Statistical Models in S, Eds JM Chambers \& TJ Hastie, London: Chapman and Hall, 1993.

33 Kahl H, Richter J \& Sommer K. Wachstum und sexuelle Reifung bei Kindern und Jugendlichen in der DDR. Wissenschaftliche Zeitschrift der Humboldt-Universität zu Berlin. Reihe Medizin 1988 37 185-186.

34 Kurth B-M, Kamtsiuris P, Hoelling H, Schlaud M, Doelle R, Ellert U, Kahl H, Knopf H, Lange M, Mensink GBM, Neuhauser H, Schaffrath-Rosario A, Scheidt-Nave C, Schenk L, Schlack R, Stolzenberg H, Thamm M, Thierfelder W \& Wolf U. The challenge of comprehensively mapping children's health in a nation-wide health survey: design of the German KiGGS-Study. BMC Public Health $2008 \mathbf{8} 196$.

35 Koch EW. Die Mindestsolls kindlicher Längengewichte nach Körperbautypen. Zeitschrift für Kinderforschung 19394749.

36 Cole TJ. The secular trend in human physical growth: a biological view. Economics and Human Biology 20031 161-168.

37 Greil H \& Schlitz A. Secular changes are different in distinct subgroups of the growing population. Anthropologischer Anzeiger 200563 45-61.

38 Farooqi IS, Matarese G, Lord GM, Keogh JM, Lawrence E, Agwu C, Sanna V, Jebb SA, Perna F, Fontana S, Lechler RI, DePaoli AM \& O'Rahilly S. Beneficial effects of leptin on obesity, $\mathrm{T}$ cell hyporesponsiveness, and neuroendocrine/metabolic dysfunction of human congenital leptin deficiency. Journal of Clinical Investigation $20021101093-1103$.

39 Welt CK, Chan JL, Bullen J, Murphy R, Smith P, DePaoli AM, Karalis A \& Mantzoros CS. Recombinant human leptin in women with hypothalamic amenorrhea. New England Journal of Medicine $2004351987-997$.

Received 20 October 2008

Accepted 28 October 2008 